\title{
La marginación de la literatura y de Hispanoamérica en el español como lengua extranjera
}

\author{
av Ingunn Hansejordet
}

El español como lengua extranjera (ELE) aparece en la escuela secundaria noruega sobre todo con la última reforma escolar, Kunnskapsløftet de 2006 (a partir de ahora: Reforma 2006). Con esta reforma el idioma, antes tan exótico, se ha difundido a casi todos los centros escolares del país. Miles de alumnos llegan a conocer las culturas hispanas, pero ciertos elementos de estas culturas quedan marginados: La literatura e Hispanoamérica. Es posible que se trate de enfermedades infantiles de una asignatura que goza de muy poca tradición escolar, pero por otro lado dicha marginación corresponde a ciertas tendencias internacionales. Si la literatura y el conocimiento de otras culturas se consideran como arenas posibles para descubrir nuevas perspectivas a lo conocido y para encuentros con el Otro, se puede decir que la marginación de la literatura y de Hispanoamérica subvierte el potencial formativo de la asignatura y, de ahí, la justificación de la misma. Aquí se comenta la situación del español en las escuelas noruegas, pero los problemas discutidos tendrán relevancia también para otras lenguas extranjeras y para otros sistemas educativos, ya que conciernen cuestiones didácticas fundamentales como ¿qué materiales y formas de trabajo podemos incluir en la clase para fomentar la competencia intercultural? y ¿cómo apoyamos el proceso de formación de cada alumno?

La marginación de la literatura de las lenguas extranjeras preocupa a varios autores noruegos. Inger Olsbu y Kari S. Salkjelsvik (2008) llaman la atención sobre la desaparición del texto literario de documentos tales como el Marco común europeo de referencia para las lenguas (Consejo de Europa 2001) y la Reforma 2006, tanto como de los métodos de ELE noruegos. Elin Nesje Vestli (2008) señala la misma ausencia de la literatura en las clases de lengua extranjera y la relaciona con una falta de énfasis en la didáctica de la literatura a nivel universitario. En cuanto a la marginación de Hispanoamérica de la asignatura ELE ésta ha sido mostrada por Liv Eide y Åse Johnsen (2006), que han analizado gran parte de los métodos usados en Noruega. Las autoras señalan una tendencia clara: España ocupa más espacio que América, y en los textos sobre América el continente se ve desde fuera, como algo extraño. La marginación tanto de la literatura como de Hispanoamérica es paradójica en la era de la competencia comunicativa, en la que se supone que la comunicación requiere también conocimientos y destrezas culturales e interculturales.

La estructura del artículo es la siguiente: El primer apartado es un repaso histórico a la enseñanza de las lenguas modernas. Se comenta el desarrollo teórico y la enseñanza que se practica en la escuela noruega en cuanto al inglés, el francés y el alemán. El paradigma 
comunicativo y la Reforma 2006 se discuten en el segundo apartado. La marginación de la literatura y de Hispanoamérica son efectos posiblemente no intencionados de la reforma y de otros mecanismos. En el tercer apartado se discute la marginación cultural a la luz de algunos ideales de la asignatura y de la educación misma: la competencia intercultural y la formación. En el último apartado se esbozan algunas ideas prácticas para incluir a voces literarias e hispanoamericanas en la clase de ELE.

\section{Repaso histórico}

Durante el siglo XX la enseñanza de las lenguas modernas ha pasado por etapas muy distintas entre sí, también en cuanto al papel de la literatura. Ya que el español está prácticamente ausente de la escuela noruega durante el siglo pasado, Hispanoamérica también lo está de este apartado.

\subsection{La literatura en la clase de lenguas modernas}

Al comienzo del siglo XX la herencia de la enseñanza del latín basada en la lectura y traducción de textos clásicos, el llamado método de gramática-traducción o método tradicional, dominaba también en la enseñanza de las lenguas modernas. ${ }^{1}$ El texto literario se consideraba una muestra elevada de lenguaje y servía como punto de partida para el análisis gramatical, el aprendizaje de estructuras y vocabulario y la adquisición de conocimientos culturales. En este paradigma se daba prioridad a los autores y textos canónicos, o sea, representantes de lo que Lourdes Miquel y Neus Sans (2004) llaman la "Cultura con mayúscula," y a las destrezas escritas: la lectura y la escritura. Tal énfasis correspondía bien al lugar de las lenguas modernas en el sistema educativo noruego: se enseñaban en la secundaria optativa, que sólo admitía a una parte del alumnado y así tenía una función selectiva para los estudios académicos. Los ideales de la formación continúan la herencia del latín, según Turid Trebbi (2005), ya que el razonamiento lógico-gramatical fomentaba la formación formal, es decir, el desarrollo de la capacidad intelectual o del método. El conocimiento de la literatura contribuía a la formación material, el aprendizaje del "contenido". A pesar de cierta difusión de ideas reformistas, como por ejemplo el uso de cuentos como punto de partida para conversaciones en la lengua meta, durante la primera mitad del siglo pasado la enseñanza en Noruega en gran medida seguía el método tradicional, según Aud Marit Simensen (2007).

Durante el cuarto de siglo que sigue, desde 1950 hasta 1975, aproximadamente, se produce una serie de cambios organizativos y pedagógicos, y Simensen llama a esta época la más agitada de las lenguas extranjeras en Noruega (2007:55). Como parte de los cambios estructurales que conducirán a la llamada sociedad de la educación, entre ellos la extensión de la educación básica a nueve años obligatorios, por primera vez todos los alumnos tienen la oportunidad de aprender una lengua extranjera, el inglés. Predominan los principios conductistas con su énfasis en el lenguaje oral y en los ejercicios diseñados para crear hábitos lingüísticos correctos, pero hay también señales directivos de dar lugar a la comunicación y al contenido. En el paradigma audio-lingual la literatura tiene poca cabida, ya que los manuales contienen textos escritos principalmente para introducir vocabulario de uso diario y para modelar estructuras, de manera que la lectura se concibe como un "complemento' de las

\footnotetext{
${ }^{1}$ Las lenguas modernas que tradicionalmente se ofrecen en Noruega son el alemán, el francés y el inglés.
} 
destrezas orales", según María José Hernández (2007 (1991):4). Se cultiva la lectura como descodificación, un procesamiento bottom up que da prioridad a los aspectos formales.

Desde alrededor de 1975, a nivel internacional, cambian profundamente la conceptualización y la didáctica de las lenguas extranjeras, y se desarrolla otro enfoque centrado en el aprendiz y en el proceso de aprendizaje. Con la influencia de la psiología cognitiva y de teorías literarias como la estética de la recepción cambia también la conceptualización de la lectura. En la enseñanza del inglés se ve en las últimas décadas del siglo XX una vuelta a la lectura como una manera de obtener un input significativo (Simensen 2007:122). La lectura de textos más largos como cuentos y novelas claramente señala un giro hacia el procesamiento top down con más énfasis en el contenido. Para la enseñanza del inglés en Noruega se establecen objetivos y métodos comunicativos, un desarrollo empujado también por la edad cada vez más baja de los principiantes.

\subsection{El alemán y el francés: "Asignaturas élite"}

Sin embargo, los cambios organizativos y metodológicos señalados no afectaron tanto a las otras lenguas extranjeras de la escuela noruega. Durante todo el siglo pasado siguieron vigentes en la enseñanza del alemán y del francés la herencia del método tradicional y los antiguos ideales de formación: La segunda lengua extranjera mantenía su posición como una asignatura élite (Trebbi 2005), quedándose al margen de la enseñanza obligatoria. Con la reforma del 1974 (Mønsterplan for grunnskolen 1974), se puso fin al sistema de agrupar a los alumnos de la secundaria básica según sus habilidades, pero por otro lado se estableció una dinámica que hizo que la enseñanza de la segunda lengua extranjera siguiera más o menos como antes. El alemán y el francés ahora se definieron como asignaturas optativas (valfag) sin exámenes y sin consecuencias para la admisión a la secundaria superior.

La situación de la segunda lengua extranjera en el último cuarto del siglo veinte es, por consiguiente, paradójica. Según una especie de lógica circular se mantiene el enfoque gramatical, ya que la asignatura es optativa y los alumnos, si les parece difícil, libremente pueden dejarla por la artesanía, el baloncesto, la mecánica u otra opción práctica o estética. Esto no quiere decir que la asignatura no cambie nada: Se introducen ejercicios estructurales y reproductivos, se pone más énfasis que antes en el lenguaje oral, a la vez que se reemplazan, en gran medida, los textos literarios por textos pragmático-funcionales (Trebbi 2005). No obstante, dado su estatus como asignaturas optativas, el alemán y el francés no llaman mucho la atención de los formadores de profesores ni tienen prioridad en la lucha por los recursos en cada escuela. A pesar de la creciente internacionalización general, hacia finales del siglo XX cada vez menos alumnos cursan una lengua optativa en la secundaria básica (Speitz y Lindemann 2002), una tendencia que empieza a preocupar a las autoridades. La reforma introducida en la última década del siglo tampoco mejora la situación.

\subsection{La Reforma 1994/1997: El valor de la literatura}

Con la reforma en 1994 de la educación secundaria superior (Reform 94) y en 1997 de la educación básica (L-97) se pusieron en vigencia unos planes para las lenguas extranjeras que valoraban la literatura como un método para trabajar con la competencia comunicativa "en un 
sentido más profundo" (Reform 94, B/C-språk, cap. 1.5). ${ }^{2}$ En el plan de la secundaria superior, que abarca todas las segundas lenguas extranjeras, la lectura se concibe como "un estímulo importante para el desarrollo personal," y la literatura como una vía de acceso a conocimientos de la cultura de la lengua meta (ibid.). Para la secundaria básica hay un plan específico para cada uno de los idiomas alemán, francés y finlandés, y cada plan menciona autores, títulos y géneros tales como cuentos de hadas, literatura infantil, poemas o extractos de novelas ( $L-97$, “Tilvalgsspråk"), asegurando así la presencia de la literatura entre los textos que se deben leer en clase. De esta reforma Olsbu y Salkjelsvik destacan cómo se integra la lectura con otras destrezas, como la escritura en varios géneros y la comunicación oral (2008:867). La presencia del español en la secundaria básica todavía es casi nula, mientras que se enseña en algunos centros de la secundaria superior, sobre todo en las ciudades.

\section{La Reforma 2006}

Con esta reforma se introduce el español en casi todos los centros, tanto en la secundaria básica como en la superior. Las asignaturas de lenguas extranjeras representan, a nivel de planes, un paradigma comunicativo muy cercano al Marco común europeo de referencia (Consejo de Europa 2001). Con esta reforma se intentó que casi todos los alumnos, a partir del octavo curso (con 14 años de edad), cursaran una segunda lengua extranjera. ${ }^{3}$ En la mayoría de las escuelas esto quiere decir alemán, francés o español, aunque en algunos sitios se ofrecen también otras opciones. Para todas las segundas lenguas extranjeras se usa el mismo plan general titulado Fremmedspråk (Lengua extranjera). ${ }^{4}$

\subsection{Acercamiento práctico a objetivos generales - competencias y comunicación}

Una intención de la reforma parece ser el poner fin a la idea de las lenguas extranjeras como una asignatura teórica, difícil y elitista. Los documentos directivos postulan que la enseñanza debe tener "un acercamiento práctico" (Utdannings- og forskingsdepartementet 2005:43). Los objetivos son generales y no específicos de ninguna lengua, y se expresan mediante listas de habilidades parecidas a las descripciones de los niveles A1-C2 del Marco de referencia. Dos ejemplos del Nivel I: Bajo el título "Comunicación” el alumno debe ser capaz de "comprender y usar un vocabulario que cubre situaciones cotidianas." Bajo el título "Lengua, cultura y sociedad" el alumno debe ser capaz de "comparar algunos aspectos de tradiciones, costumbres y maneras de vivir en el área lingüística y en Noruega" (Kunnskapsdepartementet 2006:3 5). Una consecuencia del alcance general de los objetivos es que no se especifican países, épocas, variantes lingüísticas, tiempos verbales, fenómenos culturales, autores, textos ni otros elementos del contenido de la asignatura. El plan no excluye, ni especifica.

\footnotetext{
${ }^{2}$ Todas las traducciones de planes de estudio y demás documentos oficiales son propias.

${ }^{3}$ El gobierno que preparó la reforma propuso hacer obligatorio el estudio de una segunda lengua extranjera a partir del octavo curso. Con el cambio de gobierno en 2005 se introdujo una alternativa optativa de profundización en inglés o en noruego.

${ }^{4}$ En la secundaria básica se cursa el Nivel I durante 3 años (con un promedio de unas 2 horas semanales). En la secundaria superior se cursa el Nivel II de la misma lengua, o bien el Nivel I de una lengua que no se haya estudiado antes, durante 2 años (unas 4 horas semanales). Los que escogieron profundización de inglés o noruego en la básica, tienen que cursar lengua extranjera en la superior: 2 años de Nivel I +1 año de Nivel II.

${ }^{5}$ De aquí en adelante las citas del plan de estudios pertenecen a esta referencia. Únicamente se mencionará a qué parte o nivel del plan pertenecen.
} 
La Reforma 2006 de parecida manera implica gran libertad en cuanto a los acercamientos didácticos. En la introducción al plan se da una sola señal metodológica: "Aprender una lengua extranjera es en primer lugar una cuestión de usar el idioma - leer, escuchar, hablar y escribir - en diferentes contextos." ("Objetivos de la asignatura"). El hecho de que en ningún lugar se mencione el término 'gramática' asimismo puede leerse como una señal de ruptura con la tradición gramatical-funcionalista de la "asignatura élite". Sin embargo, cómo operacionalizar el "acercamiento práctico," cómo usar el idioma, y para qué, son decisiones propias de la profesora, que goza de bastante libertad a la hora de escoger materiales y formas de trabajo para sus clases. En lo siguiente se discutirán algunos factores que influyen en tales decisiones.

\subsection{Marginación de la literatura en el paradigma comunicativo}

A cambio del énfasis puesto en la literatura en la Reforma 1994/1997, en la Reforma 2006 la literatura ha desaparecido, señalan Olsbu y Salkjelsvik (2008:867). La misma ausencia se observa en el Marco de referencia, que:

prácticamente no trata el tema de la literatura en el aula y entre los numerosos [25] tipos de competencia con las que trabaja no incluye la "competencia literaria," a pesar de la larga tradición que existe entre lengua y literatura en este campo. [Tampoco relaciona] el uso de textos literarios con el desarrollo de otro tipo de competencias específicas [...]. (Olsbu y Salkjelsvik 2008:866)

Dichas ausencias no significan necesariamente que no se pueda trabajar con la literatura en clase, pero su ausencia de los documentos influyentes es llamativa. En el plan noruego la literatura no se menciona como una herramienta para alcanzar otros fines, ni como un fin en sí mismo. Al terminar el Nivel I el alumno debe ser capaz de "encontrar datos relevantes y entender el contenido principal de textos escritos y orales, adaptados y auténticos, de diferentes géneros." En el Nivel II el alumno debe ser capaz de "leer textos formales e informales de diferentes géneros y explicar las ideas y actitudes del autor". De los objetivos citados se ve que el plan no distingue entre textos literarios y textos de otro tipo. No hay ninguna mención de una competencia literaria como la que Vestli sencillamente define como "leer y entender textos literarios, ver la estructura del texto y reconocer los recursos literarios" (Vestli 2008:12. Traducción propia).

El plan noruego parece partir de la idea de que la literatura es intercambiable con otros tipos de textos, y que todos los textos tienen el mismo valor didáctico. Surge la pregunta de hasta qué punto es fructífera la lectura que busca "explicar las ideas y actitudes del autor" en un cuento de Borges, por ejemplo. Los objetivos del plan parecen partir de unas ideas muy tradicionales del autor como único origen y último sentido del texto, y son más adecuados para la lectura de textos personales, comerciales o políticos que para el desarrollo de una competencia literaria en un sentido moderno. El énfasis en los textos auténticos, tan asociado al paradigma comunicativo, contribuye a la marginación de la literatura, ya que son los textos factuales los que dominan, como señala Anne-Brit Fenner: "Literature is, to a much lesser extent [than factual texts], used as material for language learning and for developing linguistic and cultural awareness" (Fenner 2001:14) (citado en Olsbu y Salkjelsvik 2008:867). 
Para explicar la marginación de la literatura del paradigma comunicativo, Olsbu y Salkjelsvik también se refieren a un desplazamiento de atención, del input al output. El enfoque por competencias da prioridad a "lo performativo," a las "capacidades (skills) observables y concretas," y deja menos espacio para el cuestionamiento y la reflexión. Como dicen las autoras: "El énfasis en lograr que el alumno resolviera las diferentes tareas asignadas ha hecho que la enseñanza se haya visto centrada en actividades eficaces y productivas en términos prácticos" (2008:868). Olsbu y Salkjelsvik señalan, con referencia a varios críticos, que el enfoque por tareas puede llevar a una enseñanza con rasgos funcionalistas o conductistas. En el panorama didáctico de las tareas y competencias, la lectura del texto literario se concibe como menos útil.

\subsection{Marginación de la literatura mediante otros mecanismos}

Además de las tendencias señaladas a nivel de planes, se da en la escuela noruega un fenómeno político-administrativo que parece fomentar el mismo clima didáctico. Se trata de un creciente énfasis en la documentación de métodos y, sobre todo, de resultados. Durante la última década se han introducido pruebas nacionales e internacionales para medir ciertas destrezas y asignaturas. ${ }^{6}$ Los resultados de dichas pruebas y de los exámenes finales se publican, los periódicos los comparan y los políticos los comentan. Todo profesor además debe producir una documentación escrita de su trabajo - la enseñanza, las pruebas y demás "situaciones de evaluación", la tutoría - en el caso de quejas o procesos judiciales. Por un lado, el plan de estudios otorga libertad y, por otro, la burocracia exige control. Todo esto puede contribuir a un clima en el que la literatura es particularmente vulnerable, ya que la lectura es un proceso "invisible," a veces lento, y en muchos casos individual, cuyos efectos no siempre se materializan inmediatamente como resultados fáciles de documentar.

Otra perspectiva a la ausencia de la literatura la ofrece Vestli (2008), quien observa una discrepancia entre la literatura como disciplina académica en las lenguas extranjeras impartidas en universidades y colegios universitarios, y la realidad de la escuela secundaria. A nivel universitario, según Vestli, la literatura mantiene una función de disciplina "élite", tradicionalmente con una orientación canónica. El problema para los profesores en vías de formación es una cuestión tanto de corpus como de métodos: Los estudios académicos incluyen pocos textos utilizables en el aula de la secundaria, y la didáctica de la literatura en gran medida es ignorada (Vestli 2008:11). Por consiguiente, las diferencias entre el nivel universitario y la escuela secundaria en cuanto a nivel lingüístico, acercamientos didácticos y selección de textos resultan insuperables para muchos profesores, que no saben cómo trabajar con textos literarios en clase.

En su análisis de la marginación de la literatura Olsbu y Salkjelsvik se refieren al plan curricular y a los libros de enseñanza (2008:867). A estos factores debería añadirse también otro que influye considerablemente en la práctica docente: el examen. Mediante el llamado efecto washback la forma y el contenido de exámenes anteriores tienden a establecer las premisas para la enseñanza como una especie de objetivos verdaderos o "plan curricular

\footnotetext{
${ }^{6}$ Las pruebas nacionales son de lectura, matemáticas e inglés. Véase http://www.udir.no/Artikler/ Nasjonaleprover/Hva-er-nasjonale-prover2/ Las pruebas internacionales PISA son de lectura, matemáticas y ciencias naturales, véase http://www.pisa.no/.
} 
escondido" (Simensen 2007:254. Traducción propia), ya que tanto los alumnos como los profesores se fijan en los aspectos de la asignatura que se piden en el examen.

Parece significativo, por consiguiente, que en la secundaria básica el examen de lengua extranjera es únicamente oral, mientras que en la superior hay un examen escrito y/o un examen oral. Una enseñanza que prepare para el examen lógicamente tendrá que incluir mucha práctica de las destrezas orales, con lo cual se fortalece una tendencia señalada por

Gunn Elin Heimark: Los profesores de lengua extranjera tienden a interpretar la competencia comunicativa como una competencia primordialmente oral, y el ideal del acercamiento práctico como una señal de dar prioridad a las destrezas orales (Heimark 2008). Sin embargo, como señalan planes anteriores y varios autores, existen innumerables posibilidades de integrar la lectura y los textos literarios con otras destrezas. Además, para poder hablar en el examen el alumno necesita hablar de algo, necesita input y temas para la conversación, los cuales podrían encontrarse por ejemplo en textos literarios.

\subsection{El contenido cultural en la Reforma 2006}

A diferencia de la Reforma 1994/1997 y de gran parte de la tradición, la Reforma 2006 no especifica la literatura como una posible vía a conocimientos culturales. Los objetivos bajo el título "Lengua, cultura y sociedad" son generales y abiertos, como por ejemplo "describir rasgos importantes de la cultura del área lingüística y transmitir experiencias relacionadas con esto" (Nivel II). De la misma manera que no se distinguen distintos tipos de textos, no se distingue entre distintos "rasgos" de la cultura. Ya que el plan abarca todas las segundas lenguas extranjeras, no especifica qué partes del área lingüística se deben enfatizar. Bajo este título caben temas como música, formas de tratamiento, cine, comida, deportes, geografía, estructuras sociales, literatura etcétera. Consecuentemente, la elección del contenido cultural dependerá de los intereses y conocimientos de la profesora y/o de los alumnos, además de factores prácticos como la tecnología, la biblioteca y los manuales accesibles.

\subsection{Los manuales de ELE}

A la hora de llevarse a la práctica el plan de estudios, los manuales o libros de texto son de suma importancia. En la escuela noruega ocupan una posición privilegiada: Durante gran parte de las clases de varias asignaturas, los alumnos trabajan individualmente con textos y tareas de sus manuales, según varios estudios resumidos por Dagrun Skjelbred et al. (2005). Para los profesores los manuales constituyen la herramienta principal a la hora de planificar y ejecutar las clases. Un estudio realizado bajo la Reforma 1994/1997, una reforma caracterizada por planes específicos y detallados, muestra que el $87 \%$ de los profesores utiliza los manuales para planificar sus clases, mientras que sólo el $68 \%$ utiliza el plan de estudios (Bachmann 2004 en Skjelbred et al. 2005:12). Lo que sugieren los estudios es un panorama en el que los profesores confían en los manuales como fuente de materiales y estructura para el uso de los mismos, una tendencia que probablemente no ha sido debilitada por la cantidad de profesores nuevos en el campo del español.

En los manuales de ELE, la presencia de la literatura es casi nula, señalan Olsbu y Salkjelsvik (2008), pero muy de vez en cuando aparece un breve texto literario, a menudo un poema o un refrán. Estos textos normalmente vienen sin ninguna didactización: No van acompañados de actividades de prelectura ni postlectura, a diferencia de los textos "normales" de la lección, 
que dan lugar a un abanico de ejercicios y tareas. Lo que implica tal disposición de los manuales es que los textos literarios son de poca importancia, que tienen poco que ver con el resto de la lección, y que constituyen una especie de "relleno" en el caso de que sobre tiempo o para los alumnos más interesados. Todos los factores mencionados parecen contribuir a la marginación de la literatura como algo irrelevante, inútil, y quizá, con un toque elitista.

En cuanto a la representación de Hispanoamérica en los manuales de ELE, Eide y Johnsen (2006) señalan las siguientes tendencias: España está presente en mayor grado que Hispanoamérica. En cuanto a Hispanoamérica, el énfasis se pone en la información factual (topografía, nombres de ciudades, vegetación y clima), o bien se describen elementos exóticos como fiestas populares, comidas "extrañas" o hechos "curiosos". Lo que caracteriza la representación de lo latinoamericano en estos manuales es la otredad: Es un continente "variado", "complejo", "difícilmente comprensible", "diferente". La mirada es exterior, Hispanoamérica se observa y se comenta desde fuera. Eide y Johnsen ven en estos manuales un eco de las cartas exotizantes de Cristóbal Colón, ya que dejan a europeos pronunciarse sobre los países hispanoamericanos, mientras que ningún hispanoamericano se pronuncia sobre España: "O sea, que América casi no tiene voz propia en los libros" (Eide y Johnsen 2006:9).

En un estudio sobre el tema "Cuba", Eide (2011) señala que los manuales por un lado ofrecen información turística casi a nivel de publicidad, y por otro estereotipos culturales como la salsa, el tabaco y la alegría. La situación política apenas se toca. En un mismo texto se cuenta que muchos cubanos están exiliados por falta de libertad de expresión, que no pueden dejar el país libremente, y que "la gente de Cuba es muy alegre" (Riquelme et al. 2005:61. Citado en Eide 2011:36). Algunos fenómenos políticos se mencionan de paso, pero sin explicar en qué consiste la injusticia social o qué es la revolución. De esta manera, opina Eide, se tratan de manera superficial los aspectos de la sociedad cubana que se podrían haber utilizado como puntos de partida para provocar a los alumnos, para discutir los valores democráticos o para despertar el interés por otras maneras de vivir, o sea, para fomentar el respeto y la competencia intercultural. Es interesante observar que los alumnos que utilizan estos manuales son los mismos que en las clases de ciencias sociales deben aprender a "explicar las instituciones políticas de Noruega y compararlas con las instituciones de otros países" y "dar ejemplos de y discutir la democracia como forma de gobierno [...]" (objetivos para los cursos 8 a 10, del plan de Samfunnsfag en Kunnskapsløftet). Tales objetivos son esenciales para preparar a los alumnos para la participación democrática en la sociedad, una de las metas fundamentales de la educación misma (cf. Loeringsplakaten ${ }^{7}$ ), a la cual debería contribuir incluso la asignatura de lenguas extranjeras.

\subsection{Español, España: Siesta, fiesta}

La Reforma 2006 ha dado lugar a un verdadero boom del español: Según las estadísticas del gobierno, Grunnskolens informasjonssystem (GSI), alrededor del $30 \%$ de los alumnos eligen

\footnotetext{
${ }^{7}$ Laeringsplakaten es un documento que compila y explica las leyes y los principios que rigen el sistema educativo noruego. Véase http://www.udir.no/Lareplaner/Prinsipp-for-opplaringa/Laringsplakaten/
} 
el español, frente al $25 \%$ del alemán y el $15 \%$ del francés, ${ }^{8}$ y en muchos sitios la demanda del español es superior a la oferta. ${ }^{9}$ Las causas de dicha popularidad pueden ser varias, como por ejemplo la atracción de la novedad, el factor turismo y el hecho de que muchos noruegos compran pisos de vacaciones o de jubilados en España, o la presencia en la sociedad noruega de ciertos elementos culturales supuestamente latinos como la música, el baile, la comida y el fútbol. En este panorama es posible vislumbrar unas ideas posiblemente difundidas pero raramente expresadas (en público) de que todo lo relacionado con lo hispano es fácil y ligero: el español supuestamente es más fácil de aprender que el alemán (por la gramática) y del francés (por la pronunciación), y los españoles tienen una reputación de simpáticos y relajados. Los alumnos de español se sienten menos motivados que los de alemán y francés por la posibilidad de usar el idioma para estudios posteriores o para puestos de trabajo, según Debora Carrai (2010b). Parece que el español se concibe como menos útil que los idiomas tradicionales, o es que los alumnos que lo escogen son los que menos ambiciones tienen para su futuro académico o profesional. Ambas posibilidades concuerdan con los prejuicios esbozados, o sea, con la idea del español como algo perteneciente al tiempo libre.

Los problemas señalados pueden entenderse como enfermedades infantiles, una especie de falta de madurez como asignatura escolar. En este respecto advierte Carrai que la popularidad de la asignatura, normalmente una ventaja para los profesores, "puede volverse en desventaja si hace que los estudiantes esperen que el español sea una asignatura más divertida y fácil que las lenguas tradicionalmente estudiadas en las escuelas noruegas" (Carrai 2010a:10). Si lo que connotan los alumnos con el español se limita a los conceptos 'fiesta' y 'siesta', el encuentro con un texto literario puede resultar en un choque, sobre todo si el acercamiento imita la disciplina universitaria "élite" descrita por Vestli (2008). De la misma manera, las expectativas de trabajar con un idioma que se asocia principalmente con el relajamiento, pueden constituir un obstáculo para la inclusión de otros conocimientos culturales.

\section{La formación: La meta fundamental de la educación}

La marginación de la literatura y de Hispanoamérica es problemática a nivel de asignatura: Si excluimos la literatura de la clase de lengua extranjera renunciamos a un recurso muy rico para el desarrollo de las competencias lingüística y comunicativa, como señalan Olsbu y Salkjelsvik (2008) y Vestli (2008). Los textos literarios representan, además, una posible vía a conocimientos de los aspectos culturales de la lengua meta: Mediante autores y textos canónicos, representantes de la llamada "Cultura con mayúscula," y mediante encuentros con personajes y contextos históricos o contemporáneos que representan la "cultura a secas [...] los implícitos culturales, es decir, todo aquello que para un ciudadano es tan normal, tan obvio, tan natural, que resulta invisible" (Miquel y Sans 2004). La literatura puede ofrecer visiones "desde dentro" de aquello que, visto desde fuera o a través de un manual de ELE, parece raro o incomprensible. De esta manera la literatura puede contribuir al desarrollo de la competencia intercultural. Para que los alumnos desarrollen dicha competencia hace falta llegar más allá de la perspectiva exterior que predomina en la representación de

\footnotetext{
${ }^{8}$ Las cifras varían algo de un año a otro, y de todas las lenguas extranjeras desaparecen algunos alumnos durante los tres años de la secundaria básica: Dejan la lengua extranjera por la profundización en inglés o, en menor grado, en noruego. Véase Nasjonalt senter for framandspråk i opplæringa (2010) o wis.no/gsi .

${ }^{9}$ Véase el informe sobre Noruega en la serie "El mundo estudia español" (Ministerio de educación y ciencia. Subdirección general de cooperación internacional 2009), o José María Izquierdo (2006).
} 
Hispanoamérica en los manuales, que puede fomentar prejuicios y enajenamiento más que empatía y comprensión.

El ideal de la competencia intercultural constituye una justificación fundamental de las asignaturas de lenguas extranjeras como asignaturas para todos, y no sólo para aquellos que tengan ambiciones académicas o internacionales. Las lenguas extranjeras son arenas privilegiadas para que los alumnos se encuentren con otras culturas y con otras perspectivas a su propia cultura, o en otras palabras, para su formación (Trebbi 2005). Para el filósofo Jon Hellesnes la formación tiene que ver con el diálogo, ya que la conciencia de que existe el Otro es lo que me da conceptos como "mi punto de vista" o "mi visión del mundo," conceptos necesarios para la reflexión (Hellesnes 2002. Traducción propia). De parecida manera se puede describir la formación en las asignaturas escolares como un encuentro entre el individuo y lo que lo rodea (Slagstad et al. 2003): Al adquirir o conocer un contenido que no surge del individuo mismo, sino que viene desde fuera, desde el fundamento compartido de asignatura y cultura, el individuo puede desarrollar la razón, la capacidad de autonomía y la libertad de pensamiento y acción. En la didáctica, la cuestión principal por consiguiente tiene que ser: ¿Qué elementos y aspectos de la historia de la humanidad se prestan mejor a un individuo que quiere formarse para que se refleje en ellos? (ibid.:12).

Es difícil que un manual invite a este tipo de encuentros si los textos que tratan de Hispanoamérica enfatizan la otredad como algo muy lejano, incomprensible o exótico rozando lo ridículo. Los textos "neutrales" en gran medida parecen tratar, de manera muy superficial, de jóvenes de clase media cuyas vidas giran en torno a lo que se podría denominar las tres "ces de consumo": cine, café y compras. Aunque este tipo de textos sean herramientas estupendas para aprender y practicar la comunicación diaria en la lengua extranjera, les falta una dimensión afectiva. Un texto literario, en cambio, trata de personas o situaciones reconocibles o ajenas, pero que invitan a reacciones emocionales e intelectuales. Los textos literarios cuidadosamente elegidos y/o adaptados pueden abrir puertas imaginarias a mundos desconocidos, al conocimiento cultural que Claire Kramsch (1993) llama "el tercer lugar," que no es ni la cultura meta ni el punto de partida del aprendiz, sino un proceso dialógico entre estos dos lugares. Es posible, opina Vestli, “que 'el tercer lugar' se encuentre entre las oraciones de un texto literario" (2008:17. Traducción propia).

\section{Sugerencias finales}

Entre los pocos textos literarios que aparecen en los manuales predominan los poemas, probablemente por la gran ventaja de la brevedad. Trabajar con poemas en clase puede ser una experiencia ambigua. Por un lado son textos breves, muchas veces con una voz poética claramente individualizada que invita a la identificación y a una experiencia lectora subjetiva. Por otro lado el género parece despertar cierto respeto en muchos lectores, o una sensación de enajenamiento frente a imágenes poéticas difícilmente descifrables. Una ventaja del género, sin embargo, es la flexibilidad formal y la posibilidad de suspender las normas de la sintaxis y de la lógica. Este rasgo puede aprovecharse en el aula, ya que significa que incluso los principiantes pueden escribir poemas desde el primer día. ${ }^{10}$

\footnotetext{
${ }^{10}$ Existen también cuentos breves que se pueden utilizar con principiantes, como el muy conocido "El dinosaurio" de Augusto Monterroso (1998). Véase Hansejordet (2006) para una posible didactización.
} 
Tomando como ejemplo dos poemas breves, se esbozarán, a modo de conclusión, unas sugerencias para trabajar activamente con la literatura, a la vez que se abre el aula al mundo y a ciertos fenómenos históricos. En ambos casos el trabajo sigue tres pasos destinados a activizar los esquemas cognitivos de los alumnos antes de, durante y después de la lectura, para optimar los procesos del aprendizaje.

Niños de Somalia

Yo como

Tú comes

Él come

Nosotros comemos

Vosotros coméis

¡Ellos no!

Gloria Fuertes. 1996. Mujer de verso en pecho. Madrid: Cátedra

El título puede sustituirse por otro más neutral, como "Niños pobres" o "Niños con hambre," por ejemplo si en la clase hay alumnos con vínculos personales con Somalia, ya que la idea es expresar solidaridad, y no estigmatizar. Con los alumnos podemos comentar la forma del poema invitando a una discusión sobre los rasgos característicos de un poema frente a otros géneros. Durante la lectura comparamos el poema con el paradigma original de 'comer' reflexionando sobre el efecto del cambio introducido en el sexto verso. En la fase de postlectura los alumnos escribirán sus propios poemas gramaticales o verbales. Pueden experimentar con la combinación de diferentes verbos, con los títulos y con la inclusión de palabras sencillas como no, pero, siempre, nunca, ahora, aunque, si ..., que en estructuras tan económicas aportan un gran efecto. ${ }^{11}$ Mediante pequeños recursos la palabrería aparentemente vacía del "yo como, tú comes ..." cobra valor como enunciados capaces de transmitir sentido. ${ }^{12}$ Esperamos así aumentar la conciencia entre los alumnos de la relación entre forma y contenido a la vez que practican las formas verbales dando un paso adelante hacia su automatización.

El siguiente poema, que requiere un poco más de conocimiento de vocabulario y estructuras gramaticales, tiene una relación temática con la historia reciente de muchos países latinoamericanos y con uno de los pocos fenómenos del presente que llega hasta los medios de comunicación noruegos: los emigrantes que cruzan la frontera entre México y los Estados Unidos.

Estado de exilio

muy pronto tan lejos bastante mal siempre

dificultad palabras furiosa largo

\footnotetext{
${ }^{11}$ Véase un ejemplo de didactización en Hansejordet e Izquierdo (2010).

${ }^{12}$ Véase otros poemas de la misma autora en Fuertes (1981).
} 
extraño extranjero qué más el árbol

sólo miro diferente

todo

fuera más humano

Cristina Peri Rossi. 2003. Estado de exilio. Madrid: Visor libros

Con su perspectiva del exiliado el poema puede matizar la imagen del migrante y dar una idea de la nostalgia experimentada por el extranjero en cualquier lugar. ${ }^{13}$ Después de hablar de estos temas, a lo mejor en la primera lengua de los alumnos ya que requieren un lenguaje más avanzado que el poema en sí, leemos el poema de la siguiente manera: La profesora distribuye papelitos con fragmentos del poema: "muy pronto" en uno, "tan lejos" en otro, sólo "siempre" en otro, etcétera. Cada alumno lee el suyo en voz alta en el orden señalado por la profesora, lo cual enfatizará la falta de coherencia sintáctica a la vez que pone en escena las diferentes sensaciones e ideas expresadas. De esta manera también es más fácil aclarar dudas lingüísticas respetando la composición fragmentaria del texto - los sintagmas se tratan uno por uno, sin que haga falta captar ningún sentido completo del poema. En vez de buscar "las ideas y actitudes del autor" en el texto (cf. 2.2 más arriba), los alumnos experimentan los sintagmas tal como suenan desde diferentes ángulos y en diferentes voces.

Después de leer el poema varias veces, intercambiando los papelitos para ir conociendo todos los componentes, los alumnos escriben sus propios poemas siguiendo el mismo principio. Los temas, abstractos o concretos, pueden surgir de una lluvia de ideas que resulte en una serie de títulos posibles. La intención del proceso es que los alumnos experimenten que un tema complejo puede tratarse en un lenguaje sencillo dentro de una forma poética.

Con las sugerencias esbozadas los alumnos pueden encontrarse con la literatura y con Hispanoamérica, desarrollando así una mayor conciencia del Otro y una reflexión más profunda acerca de su propia conceptualización del mundo, a la vez que desarrollan sus competencias lingüística y literaria.

Ingunn Hansejordet University of Bergen

\footnotetext{
${ }^{13}$ El tema del exilio o de la migración también ha sido tratado en un cuento conocido por ser aun más corto que "El dinosaurio", y que es más sencillo en cuanto a tiempos verbales: «El emigrante” de Luis Felipe Lomelí (2005): «-¿Olvida usted algo? -Ojalá."
} 


\section{Bibliografía}

Bachmann, Kari E. 2004. “Læreboken i reformtider - et verktøy for endring?” En Det ustyrlige klasserommet. Om styring, samarbeid og laeringsmiljø i grunnskolen. Ed. G. Imsen. Oslo: Universitetsforlaget. 119-143.

Carrai, Debora. 2010a. "Motivación y abandono en el aprendizaje del Español en Noruega I: La motivación." RedELE (Número especial. Junio 2010: Tercer Congreso Internacional de FIAPE). http://www.educacion.es/redele/FIAPEIII/ fiapeIIICongreso.shtml . 2010b. "Motivación y abandono en el aprendizaje del español en Noruega II: Resultados del estudio.” RedELE (Número especial. Junio 2010: Tercer Congreso Internacional de FIAPE). http://www.educacion.es/redele/FIAPEIII/ fiapeIIICongreso.shtml

Consejo de Europa. 2001. Marco común europeo de referencia para las lenguas: aprendizaje, enseñanza, evaluación. http://www.coe.int/T/DG4/Portfolio/?L=E\&M=/ documents intro/common_framework.html

Eide, Liv. 2011. "Salsa, sol og sosial urettferdighet." Communicare. 2011. 1. 34-36.

Eide, Liv y Åse Johnsen. 2006. "La presencia de América Latina en los métodos de E/LE en Noruega." RedELE (Número especial. Noviembre 2006. Actas del I Congreso nacional de ANPE). http://www.educacion.es/redele/Biblioteca2006/anpe/ Noruega2006.shtml

Fenner, Anne-Brit. 2001. "Dialogical Interaction with Literary Texts in Lower Secondary School.” En Cultural Awareness and Language Awareness Based on Dialogical Interaction with Texts in Foreign Language Learning, ed. A. B. Fenner. Graz/ Strasbourg: ECML/Council of Europe. 13-46.

Fuertes, Gloria. 1981. Obras incompletas. Madrid: Cátedra. 1996. Mujer de verso en pecho. Madrid: Cátedra.

Grunnskolens Informasjonssystem. 2008. www.wis.no.gsi

Hansejordet, Ingunn. 2006. "Trabajar con textos literarios en clase." RedELE. (Número especial. Noviembre 2006. Actas del I Congreso nacional de ANPE). http:// www.educacion.gob.es/redele/Biblioteca-Virtual/2006.html

Hansejordet, Ingunn y José María Izquierdo. 2010. 'Niños de Somalia' de Gloria Fuertes http://www.enmitg.com/izquierdo/literatura/fagped2010/literaturaele/gloria/ fuertes.html

Heimark, Gunn Elin. 2008. Praktisk tilncerming i fremmedspråkundervisningen: rapport fra en intervjuundersøkelse. Halden: Nasjonalt senter for framandspråk i opplæringa. http://fremmedspraksenteret.no/index.php?ID $=14151$

Hellesnes, Jon. 2002 (1969). “Ein utdanna mann og eit danna menneske.” En Grunnane. Oslo: Universitetsforlaget. 47-74.

Hernández, María José. 2007 (1991). "Del pretexto al texto: La lectura en la enseñanza/ aprendizaje de idiomas y su tratamiento en español como lengua extranjera." MarcoELE. Revista de didáctica. 2007. 5 http://www.marcoele.com/num/ 5/02e3c099660b0440d/delpretextoaltexto.pdf

Izquierdo, José María. 2006. "Instituciones al borde de un ataque de nervios. Español en Noruega, el caso de Oslo.” Biblioteca Virtual redELE. Diciembre 2007: Actas del 
Segundo Congreso Internacional de FIAPE http://www.mepsyd.es/redele/ Biblioteca2007/fiapeIId.shtml

Kramsch, Claire. 1993. Context and Culture in Language Teaching. Oxford: Oxford University Press.

Kunnskapsløftet. Kunnskapsdepartementet. 2006. http://www.udir.no/templates/udir/ TM_Læreplan.aspx?id=2100\&laereplanid $=123914$

Kunnskapsdepartementet. 2006. Loereplan i fremmedspråk http://www.udir.no/templates/udir/ TM Læreplan.aspx?id=2100\&laereplanid $=123914$

Lomelí, Luis Felipe. 2005. Ella sigue de viaje. México: Tusquets Editores.

L-97. Lareplanverket for den 10-årige grunnskolen. 1997. Det kongelege kyrkje-, utdannings- og forskingsdepartementet.

Laeringsplakaten. Utdanningsdirektoratet. Sin fecha. http://www.udir.no/Lareplaner/Prinsippfor-opplaringa/Laringsplakaten/

Ministerio de Educación y Ciencia. Subdirección general de cooperación internacional. 2009. El mundo estudia español. Noruega. Informe. Serie redELE. http://www.educacion.es/ redele/elmundo/elmundo2009.shtml

Miquel, Lourdes y Neus Sans. 2004 (1992). "El componente cultural: un ingrediente más en las clases de lengua." RedELE. Número cero, marzo 2004. http://www.educacion.es/ redele/revista/miquel sans.shtml

Monterroso, Augusto. 1998 (1959). Obras completas (y otros cuentos). Barcelona: Anagrama. Mønsterplan for grunnskolen. 1974. Kyrkje- og undervisningsdepartementet. Oslo: Aschehoug.

Nasjonalt senter for framandspråk i opplæringa. 2010. "Elevtall ungdomsskolen 2009-2010: økning for fransk, andre fag stabile.” Notat 1/2010. http://fremmedspraksenteret.no/ index.php?ID $=13790$

Olsbu, Inger y Kari S. Salkjelsvik. 2008. "Objetos perdidos: La literatura en la clase E/LE. Europa y Noruega.” Hispania 91 (4):865-876.

Peri Rossi, Cristina. 2003. Estado de exilio. Madrid: Visor libros.

Reform 94. 1994. Kyrkje-, utdannings- og forskingsdepartementet. Laereplanverket for vidaregåande opplaering (R94). http://www.udir.no/Artikler/ Lareplaner/ Lareplanverket-for-videregaende-opplaring-R94/?id=1120\#Felles\%20allmenne $\% 20 \mathrm{fag}$

Riquelme, Angella, Linda Salomonsen, Monika Saveska Knutagård, Anette de la Motte y Horacio Lizana. 2005. Amigos dos. Oslo: Gyldendal Undervisning.

Simensen, Aud Marit. 2007. Teaching a Foreign Language: Principles and Procedures. Bergen: Fagbokforlaget.

Skjelbred, Dagrun, Trine Solstad y Bente Aamotsbakken. 2005. Kartlegging av loeremidler og loeremiddelpraksis. Høgskolen i Vestfold. www-bib.hive.no/tekster/hveskrift/rapport/ 2005-01/rapp1_2005.pdf

Slagstad, Rune, Ove Korsgaard y Lars Løvlie (ed.). 2003. Dannelsens forvandlinger. Oslo: Pax.

Speitz, Heike y Beate Lindemann. 2002. "Jeg valgte tysk fordi hele familien min ville det, men jeg angrer": status for 2. fremmedspråk $i$ norsk ungdomsskole. Notodden: Telemarksforsking. 
Trebbi, Turid. 2005. "Det andre fremmedspråket: fra elitefag til et fag for alle?" En Fagenes begrunnelser. Skolens fag og arbeidsmåter i danningsperspektiv, ed. K. Børhaug, A. B. Fenner y L. Aase. Bergen: Fagbokforlaget. 103-113

Utdannings- og forskingsdepartementet. 2005. Språk åpner dører. Strategi for styrking av fremmedspråk i grunnopplaeringen 2005 - 2009.

Vestli, Elin Nesje. 2008. Fra sokkel til klasserom: Litteraturens plass $i$ fremmedspråkundervisningen. Halden: Nasjonalt senter for framandspråk i opplæringa. http://fremmedspraksenteret.no/index.php?ID=14151 